\title{
Sleep Terror Disorder
}

National Cancer Institute

\section{Source}

National Cancer Institute. Sleep Terror Disorder. NCI Thesaurus. Code C95077.

A sleep disorder characterized by abrupt awakenings from sleep with a panicky scream, accompanied by signs of autonomic arousal. There is no recall of a nightmare and the person has amnesia for the event in the morning. 